\title{
Possible benefits of singing to the mental and physical condition of the elderly
}

\author{
Katsuhisa Sakano ${ }^{1,2}$, Koufuchi Ryo ${ }^{1}$, Yoh Tamaki ${ }^{3}$, Ryoko Nakayama', Ayaka Hasaka ${ }^{1}$, Ayako Takahashi', \\ Shukuko Ebihara ${ }^{4}$, Keisuke Tozuka ${ }^{5}$ and Ichiro Saito ${ }^{1 *}$
}

\begin{abstract}
Background: The evaluation and management of stress are important for the prevention of both depression and cardiovascular disease. In addition, the maintenance of the oral condition of the elderly is essential to enable them to stay healthy, especially to prevent aspiration pneumonia and improve mental health in an aging society. Therefore, we examined the efficacy of singing on the oral condition, mental health status, and immunity of the elderly to determine if singing could contribute to the improvement of their physical condition.

Methods: Forty-four subjects (10 men, 34 women), aged 60 years or older, participated in this study. The efficacy of singing on mental health status and immunocompetence was examined by swallowing function, oral condition, blood, and saliva tests, as well as through questionnaires taken before and after singing.

Results: The results showed that the amount of saliva increased and the level of cortisol, a salivary stress marker, decreased after singing. The Visual Analog Scale (VAS) scores for feeling refreshed, comfortable, pleasurable, light-hearted, relieved, and relaxed; the tension and confusion subscale score; and the total mood disturbance (TMD) score of the Profile of Mood States (POMS) all showed improvements. Furthermore, the same tendencies were shown regardless of whether or not the subjects liked singing.
\end{abstract}

Conclusions: Our results suggest that singing can be effective in improving the mental health and oral condition of the elderly.

\section{Background}

Many recent studies have reported that stress-associated factors are detrimental to overall health [1,2]. According to a survey conducted by the Japanese Cabinet Office, approximately $60 \%$ of people experience stress in their daily lives for various reasons, including work, school, and relationships. Furthermore, the number of stressrelated depression and suicide cases is increasing every year $[3,4]$. An epidemiological study showed that people who suffered from daily stress had higher incidences of cerebrovascular disease and ischemic heart disease; therefore, the evaluation and management of stress is important for the prevention of depression and cardiovascular disease [5].

The immune system is known to be affected by stress: both the hypothalamic-pituitary-adrenal (HPA) system

\footnotetext{
* Correspondence: saito-i@tsurumi-u.ac.jp

${ }^{1}$ Department of Pathology, Tsurumi University School of Dental Medicine,

2-1-3 Tsurumi-Ku, Yokohama 230-8501, Japan

Full list of author information is available at the end of the article
}

and the locus coeruleus-noradrenalin system, which carry out endocrine reactions, are activated by stress. In the HPA system, corticotropin-releasing hormone released from the hypothalamus acts on the pituitary gland, which induces the secretion of the adrenocorticotrophic hormone from the pituitary gland. The adrenocorticotrophic hormone then stimulates the release of cortisol from the adrenal cortex. In the locus coeruleus-noradrenalin system, which originates from the locus coeruleus, the autonomic nervous system, especially the sympathetic nervous system, is activated by noradrenalin. This activation leads to both the secretion of noradrenalin from nerve endings, which then affects target tissues, and the release of catecholamine from the adrenal medulla. The levels of stress markers, such as lysozyme, cortisol, chromogranin A, amylase, and secretory immunoglobulin A, can now be measured in saliva.

In addition, the Japanese National Institute of Population and Social Security Research projected that the population will age rapidly in the coming 10 years and

\section{Biomed Central}


that, around the year 2040 , approximately $30 \%$ of the entire population will be aged 65 years or older [6]. Recent studies have shown that in such an aging society, maintaining good oral condition is essential for enabling the elderly to stay healthy, especially for the prevention of aspiration pneumonia and the improvement of mental health [7-9].

There are few reports of objective evaluations of the effects of singing, such as the effects on physical conditions and mental health status [10-12]. This lack of information prompted us to conduct a study to evaluate the effects of singing on physical conditions, including oral condition.

\section{Study design}

This prospective, open-label study was conducted according to the ethical principles of the Declaration of Helsinki. All subjects read and signed a written informed consent form, and the study was approved in advance by the Institutional Review Board of the Chiyoda Paramedical Care Clinic.

\section{Participants}

Forty-four subjects (10 men, 34 women), recruited by flyers and the Internet, aged 60 years or older, participated in this study in the Chiyoda Paramedical Care Clinic. The exclusion criteria were as follows: continuous use of medication for respiratory or cardiovascular diseases; regular use of supplements for mental health or immune status that might affect the outcome of this study; medical history of serious disease of the heart, liver, kidney, lung, or digestive organs (including gastrectomy) or in the blood, endocrine, or metabolic systems; current medical treatment; difficulty in keeping appointments; depression, a mentally unbalanced state, or frequent psychogenic reactions; or ineligibility due to other factors at the discretion of the investigator.

\section{Procedure}

This was an open-label study. The subjects were requested to not eat or drink in excess the night before the test but rather to eat and drink as they normally would, as poor physical condition or fullness can affect the amount of saliva secreted. The consumption of alcohol, the consumption of substances likely to affect salivary stress markers (green tea, coffee, black tea, cola, and energy drinks that contain a high level of caffeine), excessive exercise (physical stress can affect salivary stress markers), and the ingestion of antihistamines (known to inhibit salivary secretion) were prohibited from 9 p.m. the previous night until completion of the test. Additionally, the consumption of any substance other than water was prohibited, as other substances can affect salivary stress markers. Subjects were required to arrive
Table 1 Subject characteristics

\begin{tabular}{|c|c|c|c|c|}
\hline \multirow{2}{*}{\multicolumn{2}{|c|}{$\frac{\text { Items }}{\text { Number of subjects }}$}} & \multirow{3}{*}{$\begin{array}{l}\text { Like singing } \\
32 \\
7\end{array}$} & \multirow{3}{*}{$\begin{array}{l}\text { Diskike singing } \\
12 \\
3\end{array}$} & \multirow{3}{*}{$\begin{array}{l}\mathbf{p} \text {-value } \\
- \\
0.826\end{array}$} \\
\hline & & & & \\
\hline Sex & Male & & & \\
\hline & Female & 25 & 9 & \\
\hline \multicolumn{2}{|l|}{ Age } & $64.3 \pm 4.4$ & $63.4 \pm 2.4$ & 0.727 \\
\hline \multicolumn{2}{|c|}{ Heights (cm) } & $157.5 \pm 8.1$ & $157.6 \pm 7.7$ & 0.580 \\
\hline \multicolumn{2}{|c|}{ Weight (kg) } & $55.94 \pm 11.1$ & $62.7 \pm 11.3$ & 0.067 \\
\hline
\end{tabular}

Chi-square test was used to compare the sex and Mann-Whitney $\mathrm{U}$ test was used to compare the age, height, and weight of the subjects who like singing and those who dislike singing.

40 minutes before the test and were seated quietly in the testing room 30 minutes prior to the test, during which time they were asked to complete the pre-test VAS and POMS questionnaires. Subjects were measured for height, weight, blood pressure, and heart rate. Unstimulated saliva collection, a Saxon test, stimulated saliva collection, and blood collection were performed in that order. The subjects then sang three songs consecutively. They selected songs that they could sing in entirety. The mean singing duration was 3 minutes 50 seconds, and there was no notable deviation in the singing time (3SD). After singing, saliva and blood samples were collected in the same manner as that used for the pre-test, and the subjects once again completed the POMS and VAS questionnaires. We prepared a questionnaire sheet with the questions "Do you like singing?" and "Did you sing well?" and responses of "Yes" or "No."

\section{Measurements}

Height, weight, blood pressure, and pulse rate measurement and saliva and blood collection were all performed at the Chiyoda Paramedical Care Clinic.

The VAS scores for feeling refreshed, comfortable, pleasurable, light-hearted, relieved, and relaxed were rated on a $100-\mathrm{mm}$ vertical line anchored at the bottom (zero) with the statement "I feel nothing" and at the top

Table 2 Physiological parameters

\begin{tabular}{llll}
\hline Items & Group & Before singing & After singing \\
\hline Systolic blood & Total & $126.0 \pm 23.8$ & $130.0 \pm 23.8$ \\
pressure (mmHg) & Like singing & $129.4 \pm 25.2$ & $132.1 \pm 24.2$ \\
& Diskike singing & $116.8 \pm 17.3$ & $124.2 \pm 22.9$ \\
Diastolic blood & Total & $73.4 \pm 15.2$ & $75.3 \pm 15.2$ \\
pressure (mmHg) & & & \\
& Like singing & $74.7 \pm 15.2$ & $76.3 \pm 14.8$ \\
& Diskike singing & $69.9 \pm 15.3$ & $72.8 \pm 16.6$ \\
Pulse rate (bpm) & Total & $77.3 \pm 9.8$ & $74.6 \pm 8.5$ \\
& Like singing & $75.2 \pm 9.4$ & $72.9 \pm 7.6$ \\
& Diskike singing & $83.0 \pm 8.7$ & $79.0 \pm 9.5$ \\
\hline
\end{tabular}

Values represent the mean \pm SD. 
Table 3 Results of the two-way repeated measures ANOVA for the physiological parameters

\begin{tabular}{|c|c|c|c|c|c|c|}
\hline \multirow[t]{2}{*}{ Items } & \multicolumn{6}{|c|}{ Results of two-way repeated measures ANOVA } \\
\hline & Variables & SS (Type III) & DF & MF & $\mathrm{F}$ & p-value \\
\hline \multirow[t]{3}{*}{ Systolic blood pressure (mmHg) } & Time & 3778.705 & 1 & 3778.705 & 15.089 & $<0.001$ \\
\hline & Time* like or dislike & 0.250 & 1 & 0.250 & 0.001 & 0.975 \\
\hline & Like or dislike & 2825.875 & 1 & 2825.875 & 4.338 & 0.043 \\
\hline \multirow[t]{3}{*}{ Diastolic blood pressure $(\mathrm{mmHg})$} & Time & 87.547 & 1 & 87.547 & 1.811 & 0.186 \\
\hline & Time* like or dislike & 8.002 & 1 & 8.002 & 0.166 & 0.686 \\
\hline & Like or dislike & 292.517 & 1 & 292.517 & 0.702 & 0.407 \\
\hline \multirow[t]{3}{*}{ Pulse rate (bpm) } & Time & 172.163 & 1 & 172.163 & 11.987 & 0.001 \\
\hline & Time* like or dislike & 12.891 & 1 & 12.891 & 0.898 & 0.349 \\
\hline & Like or dislike & 843.857 & 1 & 843.857 & 6.159 & 0.017 \\
\hline
\end{tabular}

*interaction.

$(100 \mathrm{~mm})$ with the statement "I feel great." Participants were asked to look at the line and think about how their statement was affected by their singing. There were small horizontal lines along the vertical line at each centimeter interval, and participants had to mark where they felt they were along the spectrum.

In the Saxon test, saliva production is measured by weighing a folded, sterile, gauze pad both before and $2 \mathrm{~min}$ after chewing without swallowing; the low-normal value is $2 \mathrm{~g}$ [13].

In the Repetitive Saliva Swallowing Test (RSST), the patient was required to swallow saliva as often as possible while in a sitting position for $30 \mathrm{sec}$, during which time the number of clear palpations of the laryngeal prominence and elevations of the hyoid bone were counted.

The levels of the salivary markers lysozyme, chromogranin A, cortisol, secretory immunoglobulin A, and amylase were measured. Blood samples were measured for dehydroepiandrosterone sulfate (DHEA-s) levels and natural killer (NK) cell activity. To measure swallowing and oral condition, the RSST, bite force test, oral moisture content test, unstimulated saliva test, stimulated saliva test, and Saxon test were performed. The saliva and blood collections were performed in the clinic between 2:00 and 4:00 p.m. to minimize diurnal variation.

\section{Statistical analysis}

Results were considered statistically significant at the level of $\mathrm{p}<0.05$, and all tests were two-tailed. Data in the text are presented as the mean \pm S.D. A two-way repeated measures analysis of variance (ANOVA) was performed to test for the main effects corresponding to Preference ("like singing" or "dislike singing") and Time ("before singing" and "after singing"), as well as the interaction between the two. These analyses were performed using IBM SPSS (Statistical Package for the Social Sciences) Statistics Version 19 software (IBM Japan Inc., Tokyo, Japan).

\section{Results}

Forty-four subjects (10 men and 34 women), with a mean age of $64.1 \pm 3.9$ years, participated in this study. All subjects met the inclusion criteria and provided informed consent. All 44 subjects completed the study, and the characteristics of the subjects are shown in Table 1. Based on the combination of answers in the pre- and post-questionnaires, seventy-three percent of the subjects (32 subjects) provided the response combination of "I like singing" and "I sang well" (hereafter, this combination is referred to as "like singing"), and twenty-

Table 4 Swallowing and oral function

\begin{tabular}{|c|c|c|c|}
\hline Items & Group & Before singing & After singing \\
\hline \multirow[t]{3}{*}{ RSST (time) } & Total & $4.1 \pm 1.8$ & $4.3 \pm 1.8$ \\
\hline & Like singing & $4.2 \pm 1.7$ & $4.6 \pm 1.6$ \\
\hline & Diskike singing & $3.9 \pm 2.1$ & $3.5 \pm 2.1$ \\
\hline \multirow[t]{3}{*}{ Bite force test (KN) } & Total & $0.166 \pm 0.108$ & $0.171 \pm 0.098$ \\
\hline & Like singing & $0.184 \pm 0.123$ & $0.192 \pm 0.106$ \\
\hline & Diskike singing & $0.138 \pm 0.079$ & $0.139 \pm 0.079$ \\
\hline \multirow{3}{*}{$\begin{array}{l}\text { Oral moisture } \\
\text { content test }\end{array}$} & Total & $28.3 \pm 1.8$ & $28.8 \pm 1.8$ \\
\hline & Like singing & $28.3 \pm 1.8$ & $28.9 \pm 1.9$ \\
\hline & Diskike singing & $28.2 \pm 1.9$ & $28.4 \pm 1.6$ \\
\hline \multirow{3}{*}{$\begin{array}{l}\text { Unstimulated saliva } \\
\text { test (ml) }\end{array}$} & Total & $3.3 \pm 2.0$ & $4.0 \pm 2.2$ \\
\hline & Like singing & $3.3 \pm 1.9$ & $3.9 \pm 2.3$ \\
\hline & Diskike singing & $3.3 \pm 2.2$ & $4.3 \pm 2.1$ \\
\hline \multirow[t]{3}{*}{ Saxon test (g) } & Total & $4.2 \pm 1.8$ & $4.3 \pm 1.9$ \\
\hline & Like singing & $4.3 \pm 1.8$ & $4.4 \pm 2.0$ \\
\hline & Diskike singing & $3.9 \pm 1.8$ & $4.3 \pm 1.8$ \\
\hline \multirow{3}{*}{$\begin{array}{l}\text { Stimulated saliva } \\
\text { test }(\mathrm{ml})\end{array}$} & Total & $14.9 \pm 5.3$ & $15.1 \pm 5.6$ \\
\hline & Like singing & $14.9 \pm 5.8$ & $14.9 \pm 6.1$ \\
\hline & Diskike singing & $15.0 \pm 3.7$ & $15.5 \pm 4.1$ \\
\hline
\end{tabular}

Values represent the \pm SD.

23 people for the bite force test.

33 people for the oral moisture content test. 
Table 5 Results of the two-way repeated measures ANOVA for swallowing and oral function

\begin{tabular}{|c|c|c|c|c|c|c|}
\hline \multirow[t]{2}{*}{ Items } & \multicolumn{6}{|c|}{ Results of two-way repeated measures ANOVA } \\
\hline & Variables & SS (Type III) & DF & MF & $\mathbf{F}$ & p-value \\
\hline \multirow[t]{3}{*}{ RSST (time) } & Time & 0.000 & 1 & 0.000 & 0.001 & 0.978 \\
\hline & Time* like or dislike & 2.955 & 1 & 2.955 & 4.716 & 0.036 \\
\hline & Like or dislike & 7.398 & 1 & 7.398 & 1.307 & 0.259 \\
\hline \multirow[t]{3}{*}{ Bite force test $(\mathrm{KN})$} & Time & 0.000 & 1 & 0.000 & 0.135 & 0.717 \\
\hline & Time* like or dislike & 0.000 & 1 & 0.000 & 0.065 & 0.801 \\
\hline & Like or dislike & 0.027 & 1 & 0.027 & 1.385 & 0.252 \\
\hline \multirow[t]{3}{*}{ Oral moisture content test } & Time & 2.291 & 1 & 2.291 & 0.743 & 0.395 \\
\hline & Time* like or dislike & 0.627 & 1 & 0.627 & 0.203 & 0.655 \\
\hline & Like or dislike & 1.346 & 1 & 1.346 & 0.374 & 0.545 \\
\hline \multirow[t]{3}{*}{ Unstimulated saliva test (ml) } & Time & 10.611 & 1 & 10.611 & 15.872 & $<0.001$ \\
\hline & Time* like or dislike & 0.506 & 1 & 0.506 & 0.757 & 0.389 \\
\hline & Like or dislike & 1.086 & 1 & 1.086 & 0.131 & 0.719 \\
\hline \multirow[t]{3}{*}{ Saxon test (g) } & Time & 0.796 & 1 & 0.796 & 1.189 & 0.282 \\
\hline & Time* like or dislike & 0.556 & 1 & 0.556 & 0.831 & 0.367 \\
\hline & Like or dislike & 1.287 & 1 & 1.287 & 0.203 & 0.655 \\
\hline \multirow[t]{3}{*}{ Stimulated saliva test (ml) } & Time & 1.266 & 1 & 1.266 & 0.394 & 0.533 \\
\hline & Time* like or dislike & 1.068 & 1 & 10.68 & 0.333 & 0.567 \\
\hline & Like or dislike & 2.461 & 1 & 2.461 & 0.043 & 0.837 \\
\hline
\end{tabular}

*interaction.

seven percent (12 subjects) provided the response combination of "I dislike singing" and "I did not sing well" (hereafter, this combination is referred to as "dislike singing"). No significant differences were found with respect to gender, age, height, and weight between the "like singing" and "dislike singing" groups.

\section{Blood pressure and pulse rates}

The blood pressure and pulse rate results are shown in Tables 2 and 3. The two-way repeated measures ANOVA analysis indicated that systolic blood pressure was significantly increased ( $\mathrm{p}<0.01$, main effect) after singing $(130.0 \pm 23.8 \mathrm{bpm})$ compared with before singing (126.0 \pm $23.8 \mathrm{mmHg}$ ). The two-way repeated measures ANOVA also revealed that pulse rates were significantly decreased ( $\mathrm{p}<0.01$, main effect) after singing $(74.6 \pm 8.5 \mathrm{bpm})$ compared with before singing $(77.3 \pm 9.8 \mathrm{bpm})$.

The results of the two-way repeated measures ANOVA showed a significant main effect of preference (like or

Table 6 RSST

\begin{tabular}{llllll}
\hline Items & Group & $\begin{array}{l}\text { Number } \\
\text { of subjects }\end{array}$ & $\begin{array}{l}\text { Before } \\
\text { singing }\end{array}$ & $\begin{array}{l}\text { After } \\
\text { singing }\end{array}$ & p-value* \\
\hline RSST (time) & Total & 44 & $4.1 \pm 1.8$ & $4.3 \pm 1.8$ & 0.323 \\
& Like singing & 32 & $4.2 \pm 1.7$ & $4.6 \pm 1.6$ & 0.061 \\
& Diskike singing & 12 & $3.9 \pm 2.1$ & $3.5 \pm 2.1$ & 0.132 \\
\hline
\end{tabular}

Values represent the mean \pm SD.

*Wilcoxon signed rank test. dislike of singing) on both the systolic blood pressure and pulse rate. The systolic blood pressure of the "dislike singing" group was lower than that in the "like singing" group before singing; and the pulse rate of the "dislike singing" group was higher than that in the "like singing" group before singing.

\section{Swallowing and oral condition}

The swallowing and oral condition results are shown in Tables 4 and 5. The unstimulated saliva test results showed a significant increase in saliva production $(\mathrm{p}<$ 0.01 , main effect) after singing $(4.0 \pm 2.2 \mathrm{ml})$ compared with before singing $(3.3 \pm 2.0 \mathrm{ml})$.

With regard to the unstimulated saliva test results, there was no significant interaction between preference and time.

Table 7 Blood measurement

\begin{tabular}{llll}
\hline Items & Group & Before singing & After singing \\
\hline DHEA-S $(\mu \mathrm{g} / \mathrm{dL})$ & Total & $106.1 \pm 79.3$ & $106.3 \pm 77.9$ \\
& Like singing & $111.3 \pm 79.4$ & $111.0 \pm 77.3$ \\
& Diskike singing & $92.2 \pm 80.9$ & $93.5 \pm 81.7$ \\
NK cell activity (\%) & Total & $32.9 \pm 14.4$ & $32.8 \pm 14.6$ \\
& Like singing & $31.3 \pm 13.8$ & $31.5 \pm 14.6$ \\
& Diskike singing & $37.3 \pm 15.5$ & $36.3 \pm 14.5$ \\
\hline
\end{tabular}

Values represent the mean $\pm S D$. 
Table 8 Results of the two-way repeated ANOVA for blood measurement

\begin{tabular}{|c|c|c|c|c|c|c|}
\hline \multirow[t]{2}{*}{ Items } & \multicolumn{6}{|c|}{ Results of two-way repeated measures ANOVA } \\
\hline & Variables & SS (Type III) & DF & MF & $\mathbf{F}$ & p-value \\
\hline \multirow[t]{3}{*}{ DHEA-S ( $\mu \mathrm{g} / \mathrm{dL})$} & Time & 4.830 & 1 & 4.830 & 0.074 & 0.978 \\
\hline & Time* like or dislike & 11.375 & 1 & 11.375 & 0.174 & 0.036 \\
\hline & Like or dislike & 5870.000 & 1 & 5870.000 & 0.471 & 0.496 \\
\hline \multirow[t]{3}{*}{ NK cell activity (\%) } & Time & 2.125 & 1 & 2.125 & 0.126 & 0.724 \\
\hline & Time* like or dislike & 5.625 & 1 & 5.625 & 0.334 & 0.566 \\
\hline & Like or dislike & 503.296 & 1 & 503.296 & 1.260 & 0.268 \\
\hline
\end{tabular}

*interaction.

The results of the two-way repeated measures ANOVA revealed an interaction between the two main factors (time and like or dislike of singing) in the RSST.

The results of the simple main effects in the RSST are shown in Table 6. The RSST results showed a tendency to increase $(\mathrm{p}<0.061)$ after singing $(4.6 \pm 1.6$ times $)$ compared with before singing $(4.2 \pm 1.7$ times $)$ in the "like singing" group.

\section{Blood measurement}

The results of the blood measurements are shown in Tables 7 and 8. No significant difference was found in any of the measurements.

\section{Stress markers in saliva}

The changes in stress markers are shown in Tables 9 and 10. A significant decrease $(\mathrm{p}<0.01$, main effect) in cortisol was noted after singing $(0.09 \pm 0.05 \mathrm{ng} / \mathrm{ml})$ compared with the amount present before singing $(0.12 \pm$ $0.07 \mathrm{ng} / \mathrm{ml}$ ). The amount of secretory immunoglobulin
A $(\mathrm{S}-\operatorname{Ig} \mathrm{A})$ was significantly decreased $(\mathrm{p}<0.01$, main effect) before singing $(28.8 \pm 16.3 \mathrm{ng} / \mathrm{ml})$ compared with the amount after singing $(17.7 \pm 9.3 \mathrm{ng} / \mathrm{ml})$.

No significant difference in the results of any saliva test was found between the two groups of subjects who responded that they "like singing" and "dislike singing." With regard to the stress markers in saliva, there was no significant interaction between preference and time.

\section{VAS}

The VAS results for feeling refreshed, comfortable, pleasurable, light-hearted, relieved, and relaxed are shown in Tables 11 and 12 .

The results of the two- way repeated measures ANOVA indicated a significant main effect of time (before and after singing) on "refreshed," "comfortable," "pleasurable," "light-hearted," "relieved," and "relaxed" after singing compared with before singing.

The results of the two-way repeated measures ANOVA showed a significant main effect of preference (like or

Table 9 Stress markers in saliva

\begin{tabular}{|c|c|c|c|}
\hline Items & Group & Before singing & After singing \\
\hline \multirow[t]{3}{*}{ Lysozyme $(\mu \mathrm{g} / \mathrm{mL})$} & Total & $13.6 \pm 11.7$ & $13.8 \pm 9.6$ \\
\hline & Like singing & $13.7 \pm 12.8$ & $13.5 \pm 9.3$ \\
\hline & Diskike singing & $13.3 \pm 8.5$ & $14.6 \pm 10.7$ \\
\hline \multirow[t]{3}{*}{ Chromogranin A (ng/mL) } & Total & $10.8 \pm 16.6$ & $11.6 \pm 16.2$ \\
\hline & Like singing & $10.2 \pm 12.8$ & $11.0 \pm 14.5$ \\
\hline & Diskike singing & $12.6 \pm 24.7$ & $13.4 \pm 20.7$ \\
\hline \multirow[t]{3}{*}{ Cortisol (ng/mL) } & Total & $0.12 \pm 0.07$ & $0.09 \pm 0.05$ \\
\hline & Like singing & $0.12 \pm 0.07$ & $0.09 \pm 0.05$ \\
\hline & Diskike singing & $0.12 \pm 0.06$ & $0.10 \pm 0.05$ \\
\hline \multirow[t]{3}{*}{ S-lgA (ng/mL) } & Total & $28.8 \pm 16.3$ & $17.7 \pm 9.3$ \\
\hline & Like singing & $28.1 \pm 17.1$ & $17.5 \pm 9.2$ \\
\hline & Diskike singing & $30.6 \pm 14.3$ & $18.5 \pm 10.0$ \\
\hline \multirow[t]{3}{*}{ Amylase (ng/mL) } & Total & $417.8 \pm 153.4$ & $430.7 \pm 170.3$ \\
\hline & Like singing & $414.4 \pm 163.1$ & $439.1 \pm 186.7$ \\
\hline & Diskike singing & $426.8 \pm 130.0$ & $408.2 \pm 119.8$ \\
\hline
\end{tabular}


Table 10 Results of the two-way repeated measures ANOVA on stress markers in saliva

\begin{tabular}{|c|c|c|c|c|c|c|}
\hline \multirow[t]{2}{*}{ Items } & \multicolumn{6}{|c|}{ Results of two-way repeated measures ANOVA } \\
\hline & Variables & SS (Type III) & DF & MF & $\mathbf{F}$ & p-value \\
\hline \multirow[t]{3}{*}{ Lysozyme $(\mu \mathrm{g} / \mathrm{mL})$} & Time & 4.754 & 1 & 4.754 & 0.185 & 0.670 \\
\hline & Time $^{*}$ like or dislike & 9.900 & 1 & 9.900 & 0.385 & 0.539 \\
\hline & Like or dislike & 2.075 & 1 & 2.075 & 0.010 & 0.921 \\
\hline \multirow[t]{3}{*}{ Chromogranin A (ng/mL) } & Time & 10.533 & 1 & 10.533 & 0.169 & 0.683 \\
\hline & Time* like or dislike & 0.019 & 1 & 0.019 & 0.000 & 0.986 \\
\hline & Like or dislike & 100.137 & 1 & 100.137 & 0.207 & 0.652 \\
\hline \multirow[t]{3}{*}{ Cortisol (ng/mL) } & Time & 0.013 & 1 & 0.013 & 10.124 & 0.003 \\
\hline & Time* like or dislike & 0.000 & 1 & 0.000 & 0.069 & 0.795 \\
\hline & Like or dislike & 0.000 & 1 & 0.000 & 0.001 & 0.974 \\
\hline \multirow[t]{3}{*}{ S-lgA (ng/mL) } & Time & 2245.723 & 1 & 2245.723 & 35.614 & $<0.001$ \\
\hline & Time* like or dislike & 8.977 & 1 & 8.977 & 0.142 & 0.708 \\
\hline & Like or dislike & 54.564 & 1 & 54.564 & 0.185 & 0.670 \\
\hline \multirow[t]{3}{*}{ Amylase (ng/mL) } & Time & 165.859 & 1 & 165.859 & 0.026 & 0.872 \\
\hline & Time* like or dislike & 8216.001 & 1 & 8216.001 & 1.308 & 0.259 \\
\hline & Like or dislike & 1480.858 & 1 & 1480.858 & 0.031 & 0.860 \\
\hline
\end{tabular}

*interaction.

dislike of singing) on "refreshed," "pleasurable," and "relaxed." The results for "refreshed," "pleasurable," and "relaxed" feelings in the "dislike singing" group were lower than those in the "like singing" group before singing.

Table 11 Results of VAS

\begin{tabular}{llll}
\hline Items & Group & Before singing & After singing \\
\hline Refreshed & Total & $47.5 \pm 21.7$ & $65.4 \pm 19.5$ \\
& Like singing & $49.7 \pm 21.2$ & $69.9 \pm 15.8$ \\
Comfortable & Diskike singing & $41.5 \pm 22.9$ & $53.3 \pm 23.7$ \\
& Total & $45.7 \pm 22.9$ & $68.7 \pm 16.1$ \\
& Like singing & $48.1 \pm 23.2$ & $71.0 \pm 15.7$ \\
Pleasurable & Diskike singing & $39.3 \pm 21.8$ & $62.6 \pm 16.3$ \\
& Total & $48.7 \pm 23.4$ & $63.8 \pm 20.4$ \\
& Like singing & $51.3 \pm 23.0$ & $68.3 \pm 18.9$ \\
Light hearted & Diskike singing & $41.6 \pm 24.1$ & $51.6 \pm 20.0$ \\
& Total & $46.1 \pm 22.2$ & $71.6 \pm 16.9$ \\
& Like singing & $47.0 \pm 21.6$ & $76.1 \pm 12.7$ \\
Relieved & Diskike singing & $43.8 \pm 24.6$ & $59.5 \pm 20.9$ \\
& Total & $41.1 \pm 19.2$ & $78.1 \pm 13.4$ \\
& Like singing & $41.6 \pm 19.5$ & $80.2 \pm 11.6$ \\
& Diskike singing & $39.8 \pm 19.2$ & $72.5 \pm 16.8$ \\
Relaxed & Total & $41.6 \pm 19.7$ & $75.4 \pm 16.3$ \\
& Like singing & $44.3 \pm 20.8$ & $79.1 \pm 13.5$ \\
& Diskike singing & $34.7 \pm 15.1$ & $65.5 \pm 19.3$ \\
\hline Valus res & &
\end{tabular}

Values represent the mean \pm SD.

\section{POMS}

The POMS data are shown in Tables 13 and 14. A significant main effect of time (after singing vs. before singing) was noted for "tension," "confusion," and "total mood disturbance (TMD)," and there was no significant interaction between preference and time in any of the subscales or in the TMD of the POMS.

The results of the two-way repeated measures ANOVA showed a significant main effect of preference (like or dislike of singing) on "tension." The result "tension" of the "dislike singing" group was higher than that of the "like singing" group before singing.

\section{Discussion}

The results of this study demonstrate that singing can be effective in improving both the mental and oral condition of the elderly. In this study, 44 subjects (10 men and 34 women) who met the inclusion criteria were evaluated. The efficacy of singing on mental health status and immunocompetence was examined by the swallowing function, oral condition, blood, and saliva tests, as well as through questionnaires.

In the analyses of the swallowing function and mouth performance test results for all 44 subjects, a significant increase in saliva was noted in the unstimulated saliva test after singing compared with before singing. Moreover, in the saliva test, a significant decrease in the cortisol and sIgA levels was noted after singing compared with before singing.

Cortisol is a steroid hormone secreted from the zona fasciculata of the adrenal cortex and is most often studied 
Table 12 Results of the two-way repeated measures ANOVA for VAS

\begin{tabular}{|c|c|c|c|c|c|c|}
\hline \multirow[t]{2}{*}{ Items } & \multicolumn{6}{|c|}{ Results of two-way repeated measures ANOVA } \\
\hline & Variables & SS (Type III) & DF & MF & $\mathrm{F}$ & p-value \\
\hline \multirow[t]{3}{*}{ Refreshed } & Time & 4468.655 & 1 & 4468.655 & 15.785 & $<0.001$ \\
\hline & Time* like or dislike & 300.895 & 1 & 300.895 & 1.066 & 0.308 \\
\hline & Like or dislike & 2679.980 & 1 & 2679.980 & 5.164 & 0.028 \\
\hline \multirow[t]{3}{*}{ Comfortable } & Time & 9308.041 & 1 & 9308.041 & 39.507 & $<0.001$ \\
\hline & Time* like or dislike & 0.691 & 1 & 0.691 & 0.003 & 0.957 \\
\hline & Like or dislike & 1291.877 & 1 & 1291.877 & 2.409 & 0.128 \\
\hline \multirow[t]{3}{*}{ Pleasurable } & Time & 3197.558 & 1 & 3197.558 & 12.418 & 0.001 \\
\hline & Time* like or dislike & 209.954 & 1 & 209.954 & 0.815 & 0.372 \\
\hline & Like or dislike & 3058.825 & 1 & 3058.825 & 4.697 & 0.036 \\
\hline \multirow[t]{3}{*}{ Light hearted } & Time & 8766.548 & 1 & 8766.548 & 33.403 & $<0.001$ \\
\hline & Time* like or dislike & 791.963 & 1 & 791.963 & 3.018 & 0.090 \\
\hline & Like or dislike & 1711.260 & 1 & 1711.260 & 3.615 & 0.064 \\
\hline \multirow[t]{3}{*}{ Relieved } & Time & 22189.857 & 1 & 22189.857 & 98.885 & $<0.001$ \\
\hline & Time* like or dislike & 153.296 & 1 & 153.296 & 0.683 & 0.413 \\
\hline & Like or dislike & 398.322 & 1 & 398.322 & 1.225 & 0.275 \\
\hline \multirow[t]{3}{*}{ Relaxed } & Time & 18846.943 & 1 & 18846.943 & 85.365 & $<0.001$ \\
\hline & Time* like or dislike & 71.097 & 1 & 71.097 & 0.322 & 0.573 \\
\hline & Like or dislike & 2349.738 & 1 & 2349.738 & 6.028 & 0.018 \\
\hline
\end{tabular}

*interaction.

Table 13 Results of POMS

\begin{tabular}{|c|c|c|c|}
\hline Items & Group & Before singing & After singing \\
\hline \multirow[t]{3}{*}{ Tension } & Total & $5.2 \pm 3.8$ & $2.3 \pm 2.3$ \\
\hline & Like singing & $4.3 \pm 2.9$ & $2.0 \pm 2.3$ \\
\hline & Diskike singing & $7.7 \pm 4.9$ & $2.9 \pm 2.2$ \\
\hline \multirow[t]{3}{*}{ Depression } & Total & $1.2 \pm 1.7$ & $0.6 \pm 1.3$ \\
\hline & Like singing & $1.2 \pm 1.9$ & $0.7 \pm 1.3$ \\
\hline & Diskike singing & $1.0 \pm 1.2$ & $0.5 \pm 1.2$ \\
\hline \multirow[t]{3}{*}{ Anger-Hostility } & Total & $0.6 \pm 1.2$ & $0.2 \pm 0.7$ \\
\hline & Like singing & $0.5 \pm 1.2$ & $0.2 \pm 0.5$ \\
\hline & Diskike singing & $0.9 \pm 1.2$ & $0.3 \pm 1.2$ \\
\hline \multirow[t]{3}{*}{ Vigor } & Total & $6.9 \pm 4.0$ & $7.5 \pm 5.3$ \\
\hline & Like singing & $7.4 \pm 4.1$ & $8.3 \pm 5.7$ \\
\hline & Diskike singing & $5.5 \pm 3.4$ & $5.5 \pm 3.5$ \\
\hline \multirow[t]{3}{*}{ Fatigue } & Total & $2.1 \pm 3.1$ & $1.6 \pm 2.3$ \\
\hline & Like singing & $2.1 \pm 3.2$ & $1.5 \pm 2.4$ \\
\hline & Diskike singing & $2.3 \pm 2.9$ & $1.8 \pm 2.1$ \\
\hline \multirow[t]{3}{*}{ Confusion } & Total & $4.4 \pm 1.6$ & $3.4 \pm 1.6$ \\
\hline & Like singing & $4.3 \pm 1.7$ & $3.4 \pm 1.7$ \\
\hline & Diskike singing & $4.8 \pm 1.3$ & $3.3 \pm 1.3$ \\
\hline \multirow[t]{3}{*}{ TMD } & Total & $6.6 \pm 9.8$ & $0.6 \pm 9.4$ \\
\hline & Like singing & $4.9 \pm 9.7$ & $-0.5 \pm 10.2$ \\
\hline & Diskike singing & $11.1 \pm 8.8$ & $3.3 \pm 6.2$ \\
\hline
\end{tabular}

Values represent the mean \pm SD. in connection with stress. Moreover, cortisol affects the metabolic, immune, circulatory, and central nervous systems, and it is considered to be important for both mental and physical health [14]. The correlation of cortisol concentration in the saliva with that in the blood is approximately 0.90 , so there is a strong correlation between the saliva cortisol level and cortisol in the blood [15]. The cortisol level increases in response to acute mental or physical stress. The cortisol concentration in saliva increases by from $50 \%$ to $100 \%$ due to acute changes in mental health status (i.e., giving a speech), with the peak of the increase lasting 20 to 30 minutes after the stress has dissipated [16]. A reduced sIgA level in the saliva has been reported to be related to the onset of upper respiratory tract infections [17]. The relationship between stress and sIgA has been examined in research studies using saliva samples since the early days of stress research. The sIgA concentration increases by $20 \%$ to $100 \%$ due to acute stress, such as mental arithmetic or a verbal presentation, and this increase lasts from just before the initiation of the stress to immediately after the end of the stress $[18,19]$. In contrast, although there are a limited number of reports on the subject, the sIgA concentration has been reported to fall depending on the type of stress, such as viewing a terrifying image or being immersed in cold water [19]. Additionally, the sIgA level was reported to increase after exercise of short duration [19]. 
Table 14 Results of the two-way repeated measures ANOVA for POMS

\begin{tabular}{|c|c|c|c|c|c|c|}
\hline \multirow[t]{2}{*}{ Items } & \multicolumn{6}{|c|}{ Results of two-way repeated measures ANOVA } \\
\hline & Variables & SS (Type III) & DF & MF & $\mathrm{F}$ & p-value \\
\hline \multirow[t]{3}{*}{ Tension } & Time & 213.818 & 1 & 213.818 & 31.386 & $<0.001$ \\
\hline & Time* like or dislike & 27.273 & 1 & 27.273 & 4.003 & 0.052 \\
\hline & Like or dislike & 81.939 & 1 & 81.939 & 7.490 & 0.009 \\
\hline \multirow[t]{3}{*}{ Depression } & Time & 4.641 & 1 & 4.641 & 3.170 & 0.082 \\
\hline & Time $^{*}$ like or dislike & 0.004 & 1 & 0.004 & 0.003 & 0.957 \\
\hline & Like or dislike & 0.720 & 1 & 0.720 & 0.226 & 0.637 \\
\hline \multirow[t]{3}{*}{ Anger-Hostility } & Time & 3.750 & 1 & 3.750 & 4.032 & 0.051 \\
\hline & Time* like or dislike $^{*}$ & 0.250 & 1 & 0.250 & 0.269 & 0.607 \\
\hline & Like or dislike & 1.232 & 1 & 1.232 & 1.251 & 0.270 \\
\hline \multirow[t]{3}{*}{ Vigor } & Time & 3.341 & 1 & 3.341 & 0.370 & 0.547 \\
\hline & Time $^{*}$ like or dislike & 3.341 & 1 & 3.341 & 0.370 & 0.547 \\
\hline & Like or dislike & 98.455 & 1 & 98.455 & 2.947 & 0.093 \\
\hline \multirow[t]{3}{*}{ Fatigue } & Time & 4.926 & 1 & 4.926 & 1.236 & 0.273 \\
\hline & Time $^{*}$ like or dislike & 0.017 & 1 & 0.017 & 0.004 & 0.948 \\
\hline & Like or dislike & 0.614 & 1 & 0.614 & 0.055 & 0.816 \\
\hline \multirow[t]{3}{*}{ Confusion } & Time & 21.684 & 1 & 21.684 & 17.217 & $<0.001$ \\
\hline & Time* like or dislike & 1.593 & 1 & 1.593 & 1.265 & 0.267 \\
\hline & Like or dislike & 0.684 & 1 & 0.684 & 0.173 & 0.679 \\
\hline \multirow[t]{3}{*}{ TMD } & Time & 751.705 & 1 & 751.705 & 15.914 & $<0.001$ \\
\hline & Time $^{*}$ like or dislike & 24.614 & 1 & 24.614 & 0.521 & 0.474 \\
\hline & Like or dislike & 434.547 & 1 & 434.547 & 3.350 & 0.074 \\
\hline
\end{tabular}

*interaction.

The early phase of a change in sIgA concentration reflects the activity of the sympathetic nervous system and does not reflect a change in immune function, such as those carried out by B cells [20]. The relationship between $\operatorname{SIg} \mathrm{A}$ and chronic stress has also been evaluated. For example, Bosch et al. [20] summarized seven studies on the relationship between sIgA concentration and stress and showed that a student's sIgA concentration in saliva fell during examinations over a long period of time. Another study reported that the sIgA concentration remained low until 6 days to 2 weeks after the end of an examination period [21]. Taken together, the results from the present study show that the amount of saliva increased, while the salivary stress markers cortisol and IgA decreased, after singing. We believe these results indicate that singing has a relaxing effect.

From the VAS questionnaires, significant improvements were found in all of the following items after singing compared with before singing: "refreshed," "comfortable," "pleasurable," "light-hearted," "relieved," and "relaxed." The POMS questionnaires showed significant improvements in "tension," "confusion," and "TMD." We found, therefore, that singing can be effective in improving the mental state of the elderly.
A differential analysis of the groups of subjects who responded that they "like singing" and "dislike singing" showed similar results for salivary amount, salivary test results, and questionnaire responses for all 44 subjects. Regardless of whether the subject answered "like singing" or "dislike singing," the singing activity itself was considered to have contributed to improvement of the oral environment, as well as to the reduction of stress markers, except the RSST, in the saliva. Interestingly, this result indicates that we can expect greater benefits, with respect to the RSST, from singing by individuals who like singing. The results of the two-way repeated measures ANOVA showed a significant main effect of preference (like or dislike of singing) on the systolic blood pressure, pulse rate, "tension" of the POMS, and "refreshed," "pleasurable," and "relaxed" of the VAS. The pulse rate and "tension" of the POMS of the "dislike singing" group were higher than those of the "like singing" group before singing; and "refreshed," "pleasurable," and "relaxed" feelings of the "dislike singing" group were lower than those of the "like singing" group before singing. We think these results may be caused by differences in the mood of the subjects before singing. Because the subjects who like singing looked forward to singing, 
there is a possibility that the subjects who dislike singing were not looking forward to singing and thus felt tense prior to the task.

Based on the above results, singing seems to contribute to the improvement of the oral environment due to increased salivary secretion. Because stress markers in the saliva decreased and mood states of the VAS and POMS questionnaires improved, singing was shown to have contributed to stress mitigation. Therefore, singing may provide a positive impact on not only the oral environment, but also on stress relief. While significant effects were found with time, such as for the systolic blood pressure and pulse, we did observe a slight increase in blood pressure after singing. In future studies, we should confirm if this phenomenon is caused by the physical exertion of singing or by the elation resulting from singing. However, the average pulse rate of the subjects decreased slightly while singing. It is also important to assess if these results indicate a mental sedating effect. Significant effects of preference were found for the systolic blood pressure, pulse, and VAS, indicating refreshed, pleasurable, and relaxed feelings, but the POMS indicated tension. These results do not permit us to unequivocally assert that singing has a mentally stabilizing effect on a person who likes this activity. Because there were confounding factors, such as individual health conditions, we can only conclude that good health, an enjoyment of singing, and mental stability tend to be correlated.

Although no improvement was noted in swallowing function, immunity test (NK cell activity), and endocrine test (DHEA-s) results, these would be expected to be increased not by singing on just one occasion, but by continuous participation in singing. The results for lysozyme, chromogranin A, and amylase were inconclusive; however, significant differences were found in cortisol and S-IgA levels. We speculate that the reasons for these smaller than expected changes are the shortness of the observation time and limits to the sensitivity of these tests.

Because the results of this study show that one singing session allowed short-term, continuous improvement in mental health status and mood, further study is required to evaluate the effect of singing in daily life on body functions, including swallowing function and immune and endocrine conditions.

\section{Conclusions}

In this study, the beneficial effects of singing on mental health status and immunocompetence were examined using swallowing function, oral condition, blood, and saliva tests, as well as through questionnaires taken before and after singing. The results of these tests suggest that singing can be effective in improving the mental and oral condition of the elderly.
Competing interests

The authors declare that they have no competing interests.

\section{Authors' contributions}

KY conceived the study, participated in the design of the study, carried out data collection and drafted the manuscript. YT performed the statistical analysis. KR and NA and AH and AT and ES and KT participated in the design of the study and carried out data collection. IS looked over the study. All authors read and approved the final manuscript.

\section{Author details}

${ }^{1}$ Department of Pathology, Tsurumi University School of Dental Medicine,

2-1-3 Tsurumi-Ku, Yokohama 230-8501, Japan. ${ }^{2}$ PREMEDiCO Co, Ltd. 4 F Chushin Build. 3-3-5, Chiyoda-ku, Tokyo 101-0047, Uchikanda, Japan. ${ }^{3}$ Department of Health and Welfare Services, National Institute of Public Health, 2-3-6 Minami, Wako-shi, Saitama 351-0197, Japan. ${ }^{4}$ Chiyoda Paramedical Care Clinc, 2F Chushin Build. 3-3-5, Chiyoda-ku, Tokyo 101-0047, Uchikanda, Japan. ${ }^{5}$ Daiichikosho Co, Ltd. 5-5-26 Kitashinagawa,

Shinagawa-ku, Tokyo 141-8701, Japan.

Received: 5 August 2013 Accepted: 12 May 2014

Published: 21 May 2014

\section{References}

1. Danner DD, Snowdon DA, Friesen WV: Positive emotions in early life and longevity: findings from the nun study. J Pers Soc Psychol 2001, 80:804-813.

2. Veenhoven R: Healthy happiness: effects of happiness on physical health and the consequences for preventive health care. J Happiness Stud 2008, 9:449-469.

3. Japanese cabinet office. http://www5.cao.go.jp/seikatsu/senkoudo/h20/ 20senkou_summary.pdf [Article in Japanese].

4. Health and Welfare Statistics Association: Vital statistics in 2002. Vital Statistics of Japan 2002. http://www.hws-kyokai.or.jp/ [Article in Japanese].

5. Iso H, Date C, Yamamoto A, Toyoshima H, Tanabe N, Kikuchi S, Kondo T, Watanabe Y, Wada Y, Ishibashi T, Suzuki H, Koizumi A, Inaba Y, Tamakoshi A, Ohno Y: Perceived mental stress and mortality from cardiovascular disease among Japanese men and women: the Japan Collaborative Cohort Study for Evaluation of Cancer Risk Sponsored by Monbusho (JACC Study). Circulation 2002, 106:1229. lation.

6. National Institute of Population and Social Security: Future population of Japan. Research Population Projections for Japan (January 2012) 2011. http://www.ipss.go.jp/site-ad/index_english/esuikei/ppfj2012.pdf.

7. Castronuovo E, Capon A, Di Lallo D: Oral health of elderly occupants in residential homes. Ann lg 2007, 19:463-472 [Article in Italian].

8. Simons D, Brailsford S, Kidd EA, Beighton D: Relationship between oral hygiene practices and oral status in dentate elderly people living in residential homes. Community Dent Oral Epidemiol 2001, 29:464-470.

9. Kiyak HA, Grayston MN, Crinean CL: Oral health problems and needs of nursing home residents. Community Dent Oral Epidemiol 1993, 21:49-52.

10. Tamplin J, Baker FA, Grocke D, Brazzale DJ, Pretto JJ, Ruehland WR, Buttifant M, Brown DJ, Berlowitz DJ: Effect of singing on respiratory function, voice, and mood after quadriplegia: a randomized controlled trial. Arch Phys Med Rehabil 2013, 94:426-434.

11. Pai I, Lo S, Wolf $D$, Kajieker A: The effect of singing on snoring and daytime somnolence. Sleep Breath 2008, 12:265-268.

12. Ojay A, Ernst E: Can singing exercises reduce snoring? A pilot study. Complement Ther Med 2000, 8:151-156.

13. Kohler PF, Winter ME: A quantitative test for xerostomia. The Saxon test, an oral equivalent of the Schirmer test. Arthritis Rheum 1985, 28:1128-1132.

14. Sapolsky RM, Romero LM, Munck AU: How do glucocorticoids influence stress responses? integrating permissive, suppressive, stimulatory, and preparative actions. Endocr Rev 2000, 21:55-89.

15. Kirschbaum C, Hellhammer DH: Salivary cortisol in psychobiological research: an overview. Neuropsychobiology 1989, 22:150-169.

16. Kudielka BM, Buske-Kirschbaum A, Hellhammer DH, Kirschbaum C: HPA axis responses to laboratory psychosocial stress in healthy elderly adults, younger adults, and children: impact of age and gender. Psychoneuroendocrinology 2004, 29:83-98. 
17. Jemmott JB 3rd, McClelland DC: Secretory IgA as a measure of resistance to infectious disease: comments on Stone, Cox, Valdimarsdottir, and Neale. Behav Med 1989, 15:63-71.

18. Ring C, Harrison LK, Winzer A, Carroll D, Drayson M, Kendall M: Secretory immunoglobulin A and cardiovascular reactions to mental arithmetic, cold pressor, and exercise: effects of alpha-adrenergic blockade. Psychophysiology 2000, 37:634-643.

19. Spangler G: Psychological and physiological responses during an exam, and their relation to personality characteristics. Psychoneuroendocrinology 1997, 22:423-441.

20. Bosch JA, Ring C, de Geus EJ, Veerman EC, Amerongen AV: Stress and secretory immunity. Int Rev Neurobiol 2002, 52:213-253.

21. Deinzer R, Kleineidam C, Stiller-Winkler R, Idel H, Bachg D: Prolonged reduction of salivary immunoglobulin $\mathrm{A}(\mathrm{s} \lg \mathrm{A})$ after a major academic exam. Int J Psychophysiol 2000, 37:219-232.

doi:10.1186/1751-0759-8-11

Cite this article as: Sakano et al:: Possible benefits of singing to the mental and physical condition of the elderly. BioPsychoSocial Medicine 2014 8:11.

\section{Submit your next manuscript to BioMed Central and take full advantage of:}

- Convenient online submission

- Thorough peer review

- No space constraints or color figure charges

- Immediate publication on acceptance

- Inclusion in PubMed, CAS, Scopus and Google Scholar

- Research which is freely available for redistribution 